\author{
SERIES "RECENT DEVELOPMENTS IN PULMONARY INFECTIONS" \\ Edited by M. Woodhead and T. Schaberg \\ Number 3 in this Series
}

\title{
Fungal infections in transplant recipients
}

\author{
L.P. Nicod*, J-C. Pache", N. Howarth
}

Fungal infections in transplant recipients. L.P. Nicod, J-C. Pache, N. Howarth. (C)ERS Journals Ltd 2001.

ABSTRACT: Fungi are ubiquitous and the respiratory tract is exposed to aerosolized spores of both fungi that are "pathogenic" even in the normal host, such as Cryptococus neoformans, and those that are "opportunistic", such as Candida and Aspergillus species, among others. Although these latter species may occasionally form fungal balls or induce allergic phenomena in the normal host, they produce more invasive diseases in immunosuppressed patients. Among these diseases, pseudomembranous aspergillosis has recently been described.

The diagnostic approach to these entities, and, in particular, the thin dividing line between colonization and infection are addressed, along with the diagnostic value of the various procedures.

New prophylactic regimens are reviewed such as the possibility of using amphotericin aerosols in combination with systemic azole administration.

The authors would emphasize the importance of restoring lung defences by not only decreasing immunosuppressive regimens but also considering the use of newly available recombinant cytokines such as growth factors, to reduce neutropenia, for instance, in addition to antifungal drugs when infection is diagnosed. However, immunomodulation procedures are far from being well established.

Eur Respir J 2001; 17: 133-140.

Fungi are ubiquitous in nature and their constant aerosol exposure to respiratory tissue is unavoidable. Some, such as Cryptococcus neoformans and, in North America, Blastomyces, Coccidioides immitis or Histoplasma capsulatum are "pathogenic" even in the normal host. A separate group of potential fungal pathogens generally infect only those patients with abnormal host defences against infection. Among these so-called "opportunistic" fungi, Candida and Aspergillus species are those most commonly found in transplant patients [1] but others such as Torulopsis glabrata or Phycomycetes (Mucor or Rhizopus) can also occur.

The respiratory tract is an obvious portal of entry, especially soon after transplantation, not only because the immunosuppressive regimen is at its highest but also because the anatomical barrier of the mucosa is altered. Nevertheless, the gastrointestinal tract and intravascular catheters may occasionally be the source of fungal infection.

\section{Incidence of fungal infection}

Fungal infections have been reported to occur in $15-25 \%$ of patients after lung transplantation. In 1993, a $14 \%$ infection rate was reported in Pittsburgh, PA, USA, of which $56 \%$ was due to Candida and $33 \%$ to Aspergillus. The mortality rate reached $61 \%$ in these patients, with the first death occurring as early as 6 days after transplantation and a median occurrence at 44 days [2]. Although, in some series of heart/lung and lung transplant recipients, Candida infections were more frequent than those due to Aspergillus [3], in others Aspergillus infections predominated [4, 5].

In the present authors' experience of lung transplantation, $84 \%$ of patients yielded positive respiratory specimens for fungi. Candida albicans were the most frequent isolates and were found in 20 of 31 patients [6]. The second most frequently occurring fungus was Aspergillus fumigatus, isolated from 16 patients. Preoperative sputum examinations revealed $A$. fumigatus in three patients, two of whom immediately yielded a positive postoperative respiratory tract specimen, and one of whom developed invasive Aspergillus bronchitis. It is thus likely that most infections were hospitalacquired and caused by a contaminated water source, ventilation systems or construction projects. Among the Aspergillus species, A. fumigatus is the most common human pathogen. A. niger, A. terreus and A. nidulans

Previous articles in this series: No. 1: Hammerschlag MR. Chlamydia pneumoniae and the lung. Eur Respir J 2000; 16: 10011007. No. 2: Ewig S, Schäfer H, Torres A. Severity assessment in community-acquired pneumonia. Eur Respir J 2000; 16: $1193-1201$ 
are, however, also found. C. albicans was found in seven patients, one of whom yielded repeated respiratory tract and pleural fluid specimens positive for $C$. albicans immediately postoperatively. Other species, in particular $C$. norwegensis, C. lusitaniae and C. glabrata (or T. glabrata) were also isolated [6].

After liver transplantation, opportunistic fungi produce up to $37 \%$ of pneumonias, usually within 2-3 months of transplantation [7]. Invasive mycoses are also more frequent after prolonged corticosteroid or antibiotic administration, prolonged surgery, retransplantation and systemic cytomegalovirus infections [7, 8]. After kidney transplantations, $2-14 \%$ of infectious complications are caused by opportunistic fungi [9]. Opportunistic pulmonary mycoses are more common after allogeneic than autologous bone marrow transplantation. This lower incidence is due to the shorter period of neutropenia and the quicker recovery of efficient immunity [10]. Although Candida species are the most common isolates, Aspergillus is the most common cause of fungal pneumonia in patients following allogeneic bone marrow transplantation, and develops in up to $20 \%$ of them [11, 12], with the worst prognosis [13].

\section{Pathologies related to most common fungi}

\section{Aspergillus species}

The principal types of aspergillosis that affect immunocompromised patients are angioinvasive, chronic necrotizing and tracheobronchial. Other forms such as aspergilloma, allergic bronchopulmonary aspergillosis or bronchocentric granuloma are less commonly described following transplantation [14].

Invasive pulmonary aspergillosis. Classically, the major risk factors for invasive pulmonary aspergillosis include severe or prolonged neutropenia (absolute neutrophil count $<500 \times 10^{6} \cdot \mathrm{L}^{-1}$ ) and prolonged high-dose corticosteroid therapy [15]. In the absence of an effective host immune response, the spores mature into hyphae that can invade the pulmonary structures, particularly blood vessels. This results in pulmonary arterial thrombosis, haemorrhage, lung necrosis and systemic dissemination.

Macrophages and granulocytes are the major immunoregulatory cells involved in host defences against fungal infections. It has been demonstrated that corticosteroids suppress macrophage and granulocyte function, whereas little effect of the suppression of Tlymphocyte function by cyclosporin has been noted [16].

The isolation of Aspergillus from bronchoalveolar lavage fluid and/or sputum has been shown to correlate with the histopathological changes of invasive pulmonary aspergillosis in bone marrow recipients [17] in whom invasive forms cause the highest mortality [13]. Aspergillus isolation from culture of respiratory secretions, pleural fluid or ascitic fluid has also been correlated with invasive Aspergillus infection and poor outcome in recipients of both liver and kidney transplants $[18,19]$. In cases in which the diagnosis need to be proven, transbronchial biopsy is usually of little sensitivity, being as low as 20\% [20], whereas transthoracic needle biopsy or open lung biopsy provides a higher and more specific diagnostic yield [21].

Mortality rates from infections can be high (50-70\%), and patient outcome depends on the early institution of antifungal therapy, the severity of the underlying disease and the speed of granulocyte recovery [15, 22].

Invasive aspergillosis has been described as occurring following up to $18 \%$ of heart and lung transplants [23], but mortality can be reduced with pre-emptive therapy and reduced immunosuppression [6, 24].

Invasive pulmonary aspergillosis appears on radiographs as multiple ill-defined $1-2-\mathrm{cm}$ nodules that gradually coalesce into larger masses or areas of consolidation (fig. 1) [25]. An early computed tomography finding, but seen with thin collimation, is the rim of ground-glass opacity surrounding the nodules (computed tomography halo sign) [26]. This sign is, however, nonspecific and has also been described in patients with tuberculosis, mucormycosis and Wegener's granulomatosis [1]. Cavitation is usually a late finding. The intracavitary mass composed of sloughed lung and the surrounding rim of air may be seen as "the air crescent sign". Lobar consolidation is more common and less specific [27]. Pleural effusion is unusual and adenopathy rare.

Ulcerative aspergillus tracheobronchitis. Aspergillus tracheobronchitis has been well described by KRAMER et al. [4] as occurring at the bronchial anastomosis in the necrotic walls after lung transplantation, where it can cause deep ulceration or dehiscence. In the present authors' series, of the nine patients showing microscopic evidence of fungi on bronchial biopsy, two also showed clinical evidence of bronchial aspergillosis. One patient developed invasive pseudomembranous right-sided bronchial aspergillosis due to $A$. fumigatus $\sim 28$ days after transplantation. This occurred on the medial proximal part of the donor bronchi, where a limited area $(\sim 2.5 \times 3 \mathrm{~cm})$ of necrosis had been observed a few days after transplantation. The infection healed within 19 weeks of itraconozale treatment. In a second case, $\sim 3$ weeks after transplantation, a pseudomembranous aspergillosis distal to the bronchial suture of the right main bronchus obstructed $\sim 80 \%$ of the luminal area while extending into the intermediate bronchus. Under itraconozale treatment, the bronchial aspirate remained positive for 4.5 months, and the bronchus infection was healed after 6 months.

The present authors had a patient with ulcerative bronchitis due to Aspergillus $>6$ months after lung transplantation on a previously normal mucosa, while receiving high doses of inhaled steroids, and a few days after pulse steroid administration. These ulcerations healed 2 months later under itraconozale treatment (unpublished data). These forms of either invasive tracheobronchial aspergillosis or obstructive bronchopulmonary aspergillosis have been described not only after lung transplantation but also after allogeneic bone marrow transplantation and in patients with acquired immune deficiency syndrome [28, 29]. An example of a pseudomembranous aspergillosis found on autopsy is shown in figure 2. 

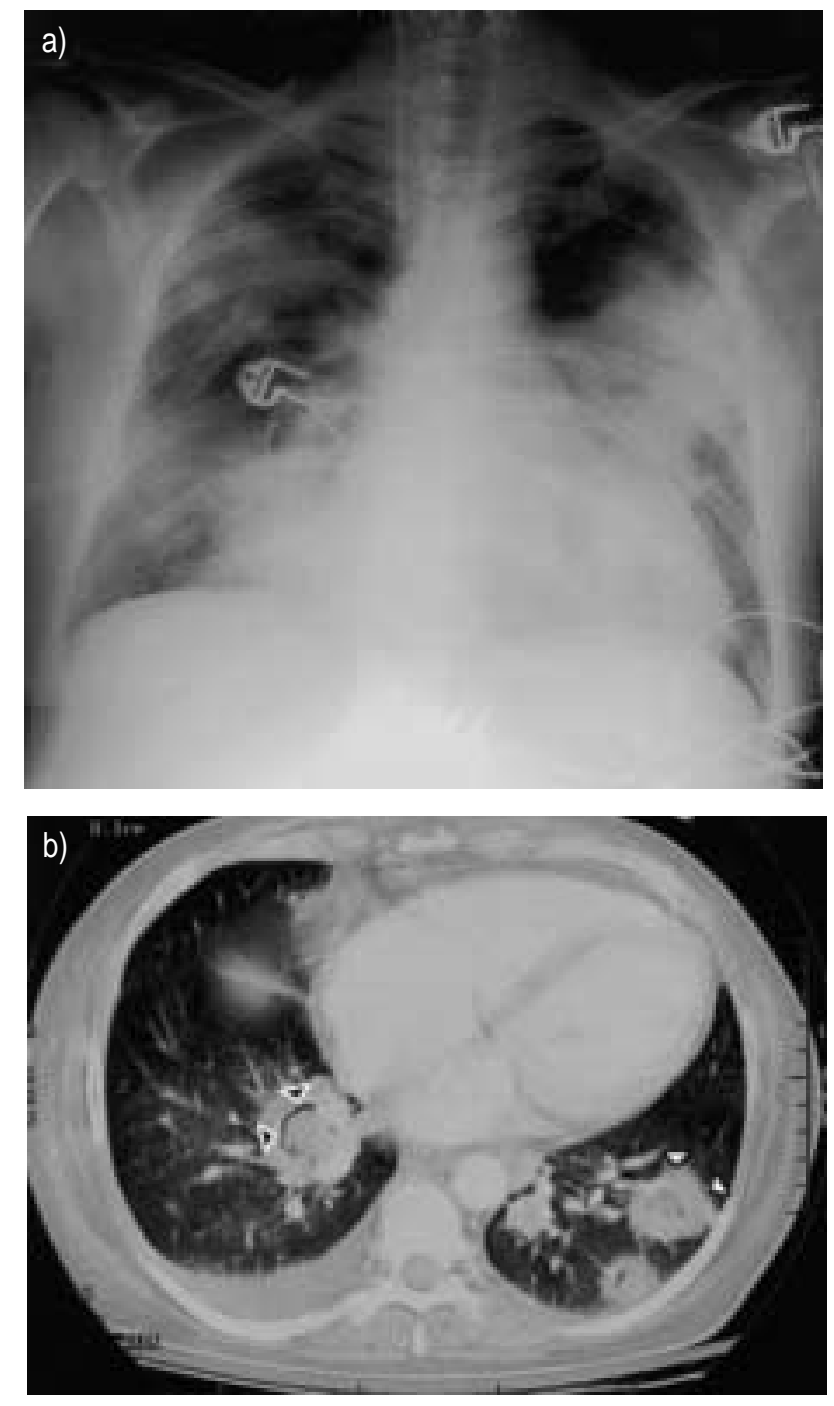

Fig. 1. - A 55-yr-old female with "leukaemia and agranulocytosis". a) Chest radiograph showing multiple bilateral focal areas of consolidatior. b) High-resolution chest computed tomography (slice thickness $1 \mathrm{~mm}$ ) revealing dense focal parenchymal nodules with surrounding air crescents (hollow arrowheads) and groundglass opacity (solid arrowheads), reflecting progressive necrotizing pneumonia. Invasive pulmonary aspergillosis was confirmed on autopsy.

Other forms of disease related to Aspergillus. Chronic necrotizing or semi-invasive aspergillosis typically occurs in patients with mild immunosuppression such as occurs in chronic obstructive pulmonary disease, sarcoidosis or underlying malignancy. It progresses slowly over a period of weeks or months. Aspergilli invade the tissues adjacent to cavities, increasing their size due to progressive necrosis. In transplantation, these slowly invasive forms are not described as distinct entities compared with the acute invasive forms.

Allergic bronchopulmonary aspergillosis has occasionally been described after transplantation [14]. Milder forms may have local consequences such as bronchocentric granulomatosis that may be underestimated. The physiopathology of allergic bronchopulmonary aspergillosis and bronchocentric granulomatosis may be better understood in the near future with the recent observation that aspergilli share epitopes similar to the cytoplasmic structures of epithelial cells. These local infections could trigger autoimmune processes [30]. It is possible that such phenomenona do occur in the lungs of transplant recipients, leading to bronchial inflammation and stenosis.

Aspergilloma can be present in pre-existing pulmonary cavities before transplantation. With immunosuppression, aspergilli can invade adjacent structures and lead to widespread disease [23]. Preventive surgical removal of such mycetoma remains a matter of debate, especially for mycetoma resulting from previous invasive aspergillosis after bone marrow transplantation [31].

\section{Candida species}

Candida species are found in the human gastrointestinal tract, from oropharynx to anus, in the female gynaecological tract and on the skin [32]. Small numbers of yeast colonies are normally present, increasing in number when the normal microbial flora is altered by antibiotics or when there is a defect in immune competence.

Disseminated candidiasis is one of the most common serious opportunistic mycoses in severely immunocompromised patients. Pulmonary candidiasis is uncommon, except in lung transplants, where they colonize and invade necrotic tissues and bronchial anastomoses. The clinical patterns range from mucocutaneous to invasive disease [23]. If isolation of Candida from the sputum of many seriously ill patients on antibiotics is very common, pneumonia is considered unusual [33]. Isolation of Candida from a patient with pulmonary infiltrates after lung transplantation should, however, not be dismissed as benign colonization, and, clearly, histological confirmation of invasive disease is essential for diagnosis and the institution of aggressive antifungal therapy. The clinical symptoms are usually nonspecific: prolonged fever despite broad-spectrum antibacterial therapy, accompanied or not by cough or haemoptysis. Chest radiographic abnomalities with disseminated candidiasis usually consist of patchy airspace consolidations in a lower lobe distribution $[34,35]$. Diffuse reticular or reticulonodular opacities are less common. Pleural effusions are reported in 25\% of patients [33]. Pulmonary cavitation and adenopathy are rare and the air crescent sign has also rarely been reported [36].

\section{Mucormycosis}

The most frequent genera within the family Mucoraceae to cause human infection are Mucor, Absidia and Rhizopus. Mucor is the most frequent, causing mucormycosis. Rhinocerebral mucormycosis in diabetic patients is perhaps the best-described infectious syndrome with Mucor, but increasing incidence of this invasive pulmonary infection among immunosuppressed patients has been reported [37]. Other groups at increased risk of pulmonary mucormycosis are 

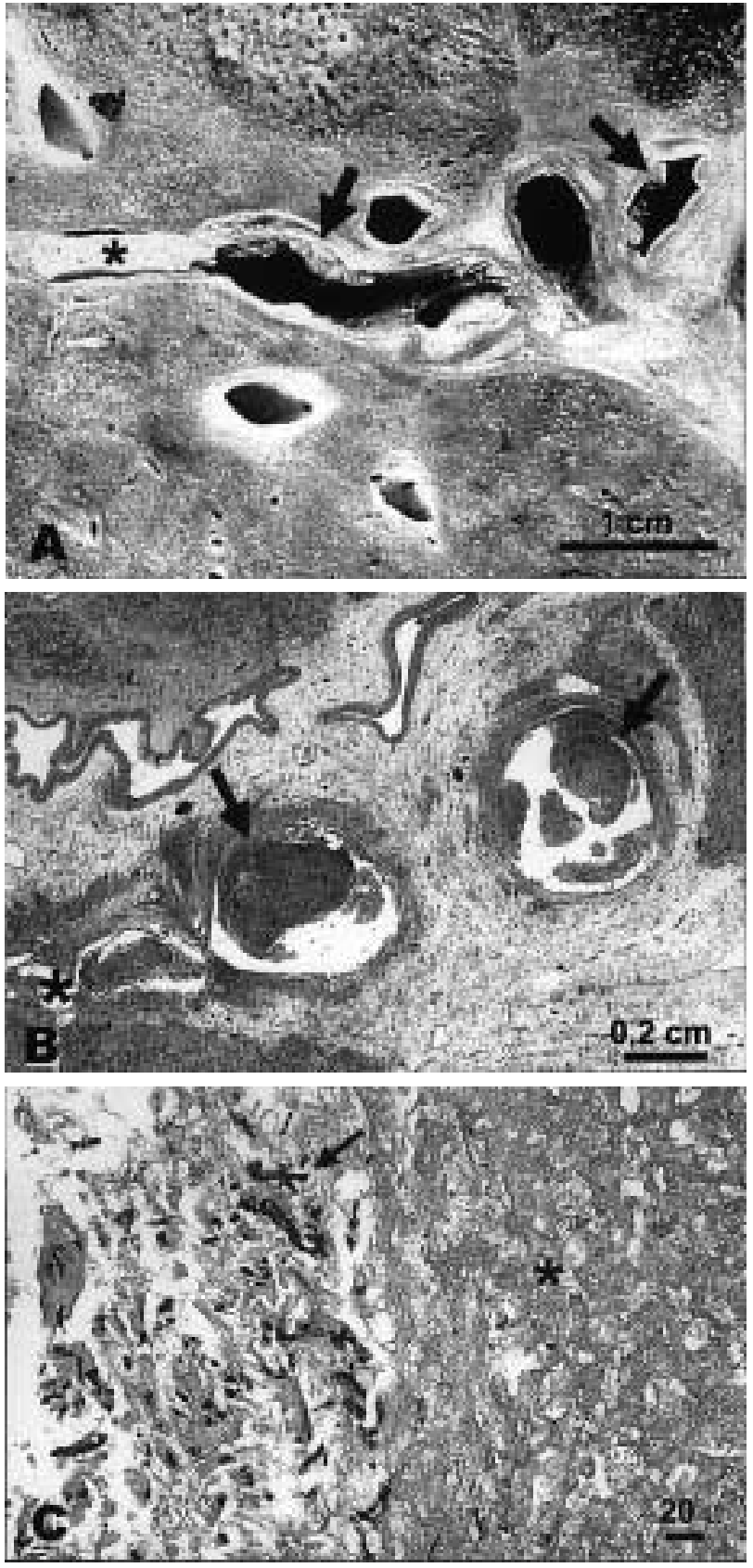

Fig. 2. - Manifestations of pseudomembranous fungal bronchitis in a lung transplantation recipient on autopsy. A) Fibrinous or pseudomembranous bronchitis (arrow) with subocclusion of the airways (asterisk indicates subocclusion of the airways by pseudomembranes); B) fibrinonecrotic material (arrow) from the airway shown in A, with subocclusion of the bronchial lumen (asterisk); and C) rare Aspergillus hyphae (arrow) in the lumen without invasion of the necrotic bronchial wall (asterisk). (Internal scale bar $\mathrm{a}=1 \mathrm{~cm} ; \mathrm{b}=0.2 \mathrm{~cm} ; \mathrm{c}=20 \mu \mathrm{m}$.)

patients with diabetes mellitus, renal failure and burns [37].

Clinically, after inhalation or aspiration of organisms, pulmonary infection with Mucor can be chronic, such as in mycetoma, or acute. Like Aspergillus, these fungi have a propensity for invasion of pulmonary arteries, causing pulmonary artery thrombosis, pulmonary infarction and haemorrhage, with possible sys- temic dissemination. Cavitation is common, but the air crescent sign is seen less frequently in these patients than in aspergillosis.

Diagnosis relies on the demonstration of the typical broad nonseptate hyphae in lung tissues obtained by biopsy, aspiration, or autopsy. Treatment with amphotericin B is recommended, but survival from acute pneumonia in the compromised host is rare.

\section{Rising opportunistic fungal infections}

T. glabrata is a yeast-like organism, normally present commensally in the human vagina. T. glabrata pneumonias have been reported in myelosuppressed patients with neoplastic disease. $T$. glabrata was isolated from the bronchoalveolar lavage fluid of three of 26 of the present authors' lung transplant patients. Pneumonia can occur and progress despite amphotericin B treatment, but apparent lung infection has also been seen to regress without specific treatment, with bone marrow recovery after bone marrow transplantation [38].

Invasive fungal infections caused by unfamiliar species are increasingly being reported in immunocompromised patients [39]. These emerging opportunistic fungi include Fusarium, a common plant pathogen; Penicillium marneffei; Trichosporon beigelii; Blastoschizomyces capitatus and Malassezia furfur. Thus Fusarium can cause disseminated infection similar to aspergillosis in profoundly neutropenic patients [40].

\section{Cryptococcosis}

C. neoformans is a fungus that exists as a yeast in both nature and tissue. The yeast cell is $4-6 \mu \mathrm{m}$ in diameter, with a capsule, which, depending on the growth conditions, can make the entire organism range from $5-20 \mu \mathrm{m}$. It is abundant in soil and pigeon excrement.

Pulmonary cryptococcosis causes symptoms ranging from none to those of overt pneumonia. The resultant radiographic lesions vary from plate-like atelectases to diffuse interstitial infiltrates, from ill-defined tiny nodules to huge space-occupying masses. The progression of the disease varies with the state of immunosuppression [41]. In immunocompromised patients, dissemination to extrathoracic sites such as the central nervous system, bone and skin is common [42]. Immunocompromised patients often show few or no pulmonary symptoms, even in the presence of radiographically evident pulmonary abnormalities [42].

Positive sputum culture does not establish the diagnosis; it is therefore prudent to rely instead on demonstration of the fungus in tissue, either microscopically or on culture. Serum cryptococcal antigen titres are not usually elevated, except in patients with disseminated disease [42].

\section{Treatment of fungal infection}

Amphotericin B is the traditional drug of choice. The most prominent disadvantage of amphotericin B is its 

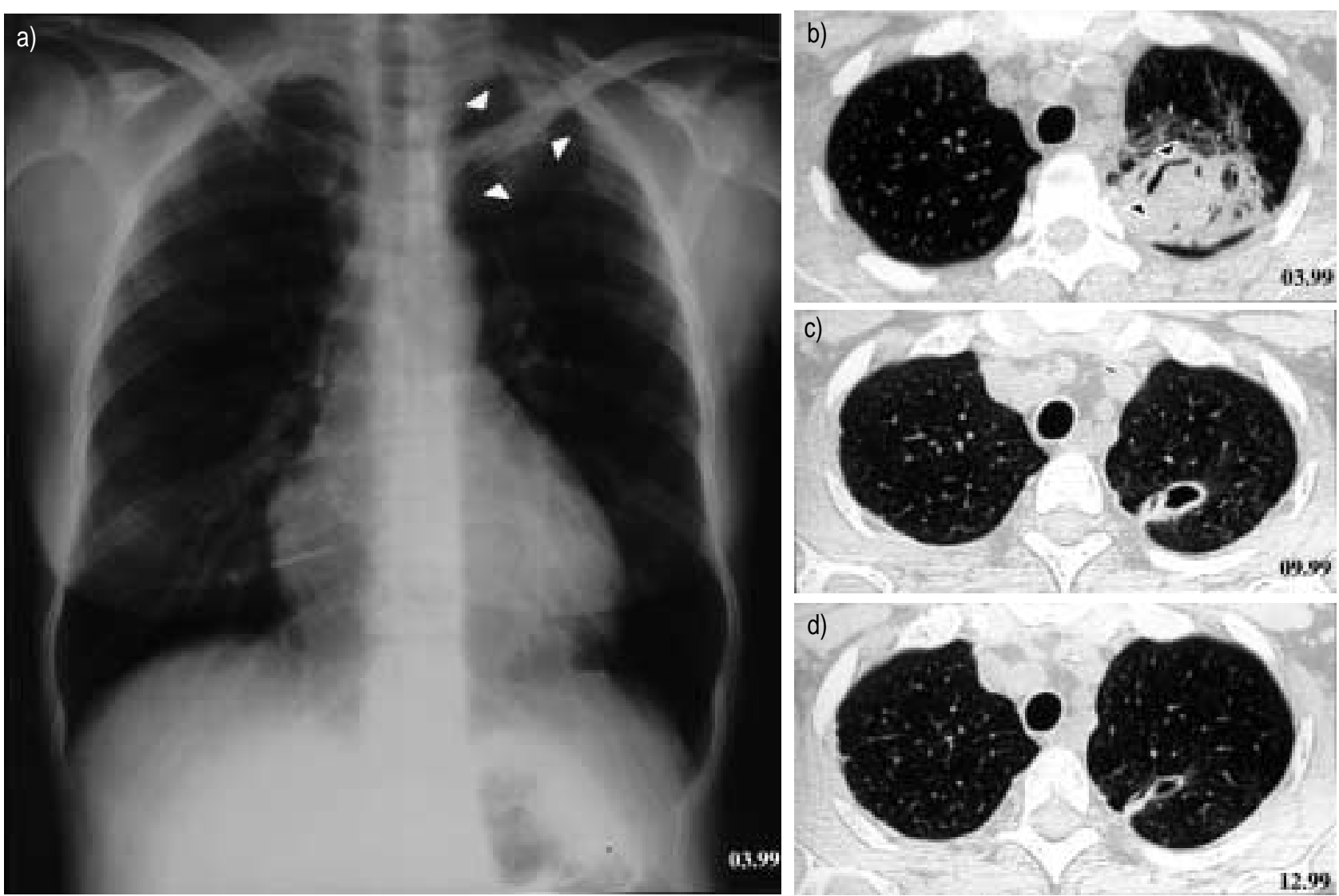

Fig. 3. - A 47-yr-old female who underwent bone marrow transplantation in February 1999 for myelodysplasia. a) The chest radiograph 1 month later shows an ill-defined retroclavicular opacity in the left upper lobe (arrowheads). b) High-resolution chest computed tomography (CT; slide thickness $1 \mathrm{~mm}$ ) reveals an area of dense focal consolidation with an air crescent (arrowheads) strongly suggestive of invasive aspergillosis. c, d) Follow-up CT examinations after 1 month of AmBisome followed by 9 months of itraconozole, after a further: c) 6 months; and d) 9 months.

nephrotoxic effect. The treatment of aspergillosis with amphotericin $\mathrm{B}$ in solid organ transplant recipients results in a higher incidence of nephrotoxicity because of the concomitant use of cyclosporin [43]. Liposomal amphotericin B (AmBisome) has far fewer side-effects and can be much more safely used in patients with solid organ transplants, despite concomitant use of cyclosporin A. In a series of 187 transplant recipients, liposomal amphotericin B was discontinued due to sideeffects in $3 \%$ of cases. The overall mean increase in serum creatinine levels was $20 \%$. Other side-effects included low serum potassium concentrations $(36 \%)$ and a rise in alkaline phosphatase levels $(26 \%)$ [44].

Liposomal amphotericin B markedly decreases the death rate due to aspergillosis in neutropenic patients after bone marrow transplantation from $90 \%$ down to $25 \%$ even when neutrophil counts are still low [45]. The antifungal efficacy of AmBisome seems to be related to its ability to target fungi rather specifically [46].

Among azoles, fluconazole has been used effectively in localized Candida infections, and may also be an option in the treatment of systemic candidiasis [47, 48], but data supporting its use in pneumonia are lacking at the present time. Itraconazole or the new azole voriconazole [49] are effective therapies against aspergillosis, candidiasis or cryptococcosis. They are well tolerated. Enzyme-inducing drugs such as rifampicin and phenytoin significantly reduce the oral bioavailability of itraconazole, and plasma monitoring of its plasma concentration is recommended when enzymeinducing agents are coadministered.

Itraconazole has been shown to be as effective as amphotericin B in small series of neutropenic patients [50], and in liver or heart transplant recipients [51, 52]. An example of the evolution of invasive aspergillosis initially treated for 1 month with AmBisome followed by 9 months of itraconazole treatment is shown in figure 3. Failure of itraconazole treatment of pulmonary aspergillosis in heart transplant recipients has been reported, but most of these patients had been maintained on high-dose steroids [53].

Modulation of immunosuppression has to be taken into account as a major component of fungal infection treatment. The use of haematological growth factors may prove to be useful in the near future in not only restoring the neutrophil count more quickly, but also increasing the capacity to contain fungal pathogens [54].

\section{Prophylaxis of fungal infections}

It is not easy to determine the pathogenic role of fungal isolates from the respiratory tract [55] i.e. to 
differentiate between infection, colonization and contamination. Several groups are very concerned by the high likelihood of disease when fungi are detected in respiratory tract specimens of either bone marrow or lung transplant recipients, especially with non-Candida strains $[2,56]$. It is important that potential transplantation candidates are screened for pre-existing fungal infections. Patients with positive cultures for Aspergillus and clinical or radiological signs suggesting an infection are usually given a therapy such as fluconazole for Candida or itraconazole and aerosolized amphotericin $\mathrm{B}$ for Aspergillus until signs of infection disappear [57].

Patients colonized with Aspergillus either before or after lung transplantation and receiving prophylaxis show a decreased rate of fungal infection. Indeed, aerosolized amphotericin B $\left(0.6 \mathrm{mg} \cdot \mathrm{kg}\right.$ body weight ${ }^{-}$ ${ }^{1} \cdot$ day $^{-1}$ ) divided into three doses and oral fluconazole $\left(400 \mathrm{mg} \cdot \mathrm{day}^{-1}\right)$ during the postoperative period prevented the early occurrence of any fungal infection in 52 lung transplant recipients [57]. Some groups have started using $15 \mathrm{mg}$ amphotericin B twice daily for 2-3 months, as prophylaxis, with excellent preliminary results and little or no toxicity. In the present authors' lung transplant patients, fungi were found posttransplantation in the lower respiratory tract specimens of 26 of $31(84 \%)$ patients, predominantly C. albicans (20 patients) and $A$. fumigatus (16 patients). Mycelia characteristic of Candida sp. or Aspergillus sp. were found in necrotic tissue at the bronchial suture in nine patients. Fluconazole $\left(200 \mathrm{mg} \cdot \mathrm{day}^{-1}\right)$ or itraconazole (200-400 mg b.i.d.) was systematically used according to presumed fungal sensitivity after the discovery of fungi in lower respiratory tract samples. The mean duration of the 38 treatments was $3.6 \pm 2$ months. After a median follow-up of 16 months, two cases of extended ulcerative and pseudomembranous $A$. fumigatus bronchitis observed early were also resolved under itraconazole treatment [6]. Postoperative pre-emptive azole therapies thus appear well tolerated and effective in lung transplant recipients.

Azoles have been shown to be safe and efficient in the prevention of some invasive fungal infections in bone marrow transplantation [58, 59]. Ketoconazole has been used in recent heart and kidney transplant studies. A cost-sparing effect was obtained by reducing the cyclosporin dosage required and because of its efficacy in preventing fungal infections and achieving a lower rejection rate $[60,61]$. However, care should be exercised not only because of drug interactions with azoles, but also because primary or secondary resistance to the antifungal drugs used may occasionally develop $[62,63]$.

\section{References}

1. Connolly JE, McAdams HP, Erasmus JJ, Rosado-deChristenson ML. Opportunistic fungal pneumonia. J Thorac Imaging 1999; 14: 51-62.

2. Paradis II, Williams P. Infection after lung transplantation. Semin Respir Infec 1993; 8: 207-215.

3. Maurer JP, Tullis DE, Grossman RF, Vellend H, Winton TL, Patterson GA. Infectious complications following isolated lung transplantation. Chest 1992; 101: 1056-1059.

4. Kramer MR, Denning DW, Marshall SE, et al. Ulcerative tracheobronchitis after lung transplantation. A new form of invasive aspergillosis. Am Rev Respir Dis 1991; 144: 552-556.

5. Laghi F, Yeldandi V, MacCabe M, Garrity ERJ. Common infections complicating lung transplantation. $N$ J Med 1993; 90: 313-319.

6. Hamacher J, Spiliopoulos A, Kurt AM, Nicod LP, and the Geneva Lung Transplantation Group. Preemptive therapy with azoles in lung transplant patients. Eur Respir J 1999; 13: 180-186.

7. George MJ, Snydman DR, Werner BG, et al. The independant role of cytomegalovirus as a risk factor for invasive fungal disease in orthotopic liver transplant recipients. Am J Med 1997; 103: 106-113.

8. Winston DJ, Emmanouilides C, Busuttil RW. Infections in liver transplant recipients. Clin Infect Dis 1995; 21: 1077-1091.

9. Sia IG, Paya CV. Infectious complications following renal transplantation. Surg Clin North Am 1998; 78: 95-112.

10. Wilczynski SW, Erasmus JJ, Petros WP, Vrdenburgh JJ, Folz RJ. Delayed pulmonary toxicity syndrome following high-dose chemotherapy and bone marrow transplantation for breast cancer. Am J Respir Crit Care Med 1998; 157: 565-573.

11. Walsh TJ, Hiemenz JW, Anaissie E. Recent progress and current problems in treatment of invasive fungal infections in neutropenic patients. Infect Dis Clin North Am 1996; 10: 365-401.

12. Worthy SA, Flint JD, Muller NL. Pulmonary complications after bone marrow transplantation: highresolution CT and pathologic findings. Radiographics 1997; 17: 1359-1371.

13. Kaiser L, Huguenin T, Lew PD, Chapuis B, Pittet D. Invasive Aspergillosis clinical features of 35 proven cases at a single institution. Medicine 1998; 77: 188-194.

14. Fitzsimmons EJ, Aris R, Patterson R. Recurrence of allergic bronchopulmonary aspergillosis in the posttransplant lungs of a cystic fibrosis patient. Chest 1997; 112: 281-282.

15. Denning DW. Diagnosis and management of invasive aspergillosis. Curr Clin Top Infect Dis 1996; 16: 277299.

16. Berenguer J, Allende MC, Lee JW, et al. Pathogenesis of pulmonary aspergillosis granulocytopenia versus cyclosporine and methylprednisone-induced immunosuppression. Am J Respir Crit Care Med 1995; 152: 1079-1086.

17. Saugier-Veber $\mathrm{P}$, Devergie A, Sulahian A, et al. Epidemiology and diagnosis of invasive pulmonary aspergillosis in bone marrow transplant patients: results of a 5 year retrospective study. Bone Marrow Transplant 1993; 12: 121-124.

18. Braun RS, Lake JR, Katzman BA, et al. Incidence and significance of Aspergillus cultures following liver and kidney transplantation. Transplantation 1996; 61: 666669.

19. Singh N, Arnow PM, Bonham A, et al. Invasive aspergillosis in liver transplant recipients in the 1990s. Transplantation 1997; 64: 716-720.

20. Pomerance A, Madden B, Burke MM, Yacoub MH. Transbronchial biopsy in heart and lung transplantation: clinicopathologic correlations. J Heart Lung Transplant 1995; 14: 761-773. 
21. Ellis ME, Spence D, Bouchama A, et al., and the Fungal Study Group. Open lung biopsy provides a higher and more specific diagnostic yield compared to broncho-alveolar lavage in immunocompromised patients. Scand J Infect Dis 1995; 27: 157-162.

22. Caillot D, Casasnovas O, Bernard A, et al. Improved management of invasive pulmonary aspergillosis in neutropenic patients using early thoracic computed tomographic scan and surgery. J Clin Oncol 1997; 15: 139-147.

23. Kanj SS, Welty-Wolf K, Madden J, et al. Fungal infections in lung and heart-lung transplant recipients. Report of 9 cases and review of the literature. Medicine 1996; 75: 142-156.

24. Nunley DR, Ohori P, Grgurich WF, et al. Pulmonary aspergillosis in cystic fibrosis lung transplant recipients. Chest 1998; 114: 1321-1329.

25. Klein DL, Gamsu G. Thoracic manifestations of aspergillosis. AJR Am J Roentgenol 1980; 134: 543-552.

26. Kuhlman JE, Fishman EK, Siegelman SS. Invasive pulmonary aspergillosis and acute leukemia: characteristic findings on CT, the CT halo sign, and the role of CT in early diagnosis. Radiology 1985; 157: 611-614.

27. Diederich S, Scadeng M, Dennis $\mathrm{CH}$, Stewart S, Flower CH. Aspergillus infection of the respiratory tract after lung transplantation: chest radiographic and CT findings. Eur Radiol 1998; 8: 306-312.

28. Logan PM, Primack SL, Miller RR, Muller NL. Invasive aspergillosis of the airways: radiographic, CT, and pathologic findings. Radiology 1994; 193 : 383-388.

29. Kemper CA, Hostetler JS, Follansbee SE, et al. Ulcerative and plaque-like tracheobronchitis due to infection with Aspergillus in patients with AIDS. Clin Infect Dis 1993; 17: 344-352.

30. Mayer C, Appenzeller U, Seelbach H, et al. Humoral and cell-mediated autoimmune reactions to human acidic ribosomal $\mathrm{P} 2$ protein in individuals sensitized to Aspergillus fumigatus P2 protein. J Exp Med 1999; 189: 1507-1512.

31. Castagnola E, Bucci B, Montinaro E, Viscoli C. Fungal infections in patients undergoing bone marrow transplantation: an approach to a rational management protocol. Bone Marrow Transplant 1996; 18: 97-106.

32. Chu FE, Armstrong D. Candida Species Pneumonia. In: Sarosi GA, Davies SF, eds. Fungal Diseases of the Lung. 2nd Edn. New York, Raven Press, 1993; 10, 125-131.

33. Pennington JE. Opportunistic Fungal Pneumonias: Aspergillus, Mucor, Candida, Torulopsis. In: Pennington JE, ed. Respiratory Infections: Diagnosis and Management. 3rd Edn. New York, Raven Press, 1994; 25, 533-549.

34. Buff SJ, McLelland R, Gallis HA. Candida albicans pneumonia: radiographic appearance. Am J Roentgenol 1982; 138: 645-650.

35. Kassner EG, Kauffman SL, Yoon JJ. Pulmonary candidiasis in infants: clinical, radiologic, and pathologic features. Am J Roentgenol 1981; 137: 707-716.

36. Watanakunakorn C. Acute pulmonary mycetoma due to Candida albicans with complete resolution. J Infect Dis 1983; 148: 1131.

37. Leher RI, Howard DH, Syphred PS, et al. Mucormycosis. Ann Intern Med 1980; 93: 93-108.

38. Aisner J, Sickles EA, Schimpff SC, Young VM, Greene WH, Wiernik PH. Torulopsis glabrata pneumonitis in patients with cancer: report of three cases. JAMA 1974; 230: 584-585.

39. Perfect JR, Schell WA. The new fungal opportunists are coming. Clin Infect Dis 1996; 22: S112-S118.

40. Martino P, Gastaldi R, Raccah R, Girmenia C. Clinical patterns of Fusarium infections in immunocompromised patients. J Infect 1994; 28: 7-15.

41. Khoury MB, Godwin JD, Ravin CE, Gallis HA, Halvorsen RA, Putman CE. Thoracic cryptococcosis: immunologic competence and radiographic appearance. Am J Roentgenol 1984; 141: 893-896.

42. Patz EF, Goodman PC. Pulmonary cryptococcosis. $J$ Thorac Imaging 1992; 4: 51-55.

43. Harari S. Current strategies in the treatment of invasive Aspergillus infections in immunocompromised patients. Drugs 1999; 58: 621-631.

44. Ringdén O, Andström E, Remberger M, Svahn B-M, Tollemar J. Safety of liposomal amphotericin B (AmBisome) in 187 transplant recipients treated with cyclosporin. Bone Marrow Transplant 1994; 14: S10S14.

45. Mills W, Chopra R, Linch DC, Goldstone AH. Liposomal amphotericin B in the treatment of fungal infections in neutropenic patients: a single-centre experience of 133 episodes in 116 patients. Br J Haematol 1994; 86: 754-760.

46. Adler-Moore J. AmBisome targeting to fungal infections. Bone Marrow Transplant 1994; 14: Suppl. 5, S3S7.

47. Anaissie E, Bodey GP, Kantarjian H, et al. Fluconazole therapy for chronic disseminated candidiasis in patients with leukemia and prior amphotericin B therapy. Am J Med 1991; 91: 142-150.

48. Kauffman CA, Bradley SF, Ross SC, Weber DR. Hepatosplenic candidiasis: successful treatment with fluconazole. Am J Med 1991; 91: 137-141.

49. Murphy M, Bernard EM, Ishimaru T, Armstrong D. Activity of voriconazole against clinical isolates of Aspergillus species and its effectiveness in an experimental model of invasive pulmonary aspergillosis. Antimicrob Agents Chemother 1997; 41: 696-698.

50. Van't Wout JW, Novakova I, Verhagen CAH, Fibbe WE, de Pauw BE, van der Meer JWM. The efficacy of itraconazole against systemic fungal infections in neutropenic patients: a randomised comparative study with amphotericin B. J Infect 1992; 22: 45-52.

51. Denning DW, Tucker RM, Hanson LH, Stevens DA. Treatment of invasive aspergillosis with itraconazole. Am J Med 1989; 8: 791-800.

52. Viviani MA, Tortorano AM, Pagano A, et al. European experience with itraconazole in systemic mycoses. J Am Acad Dermatol 1990; 23: 587-593.

53. Nanas JN, Saroglou G, Anastasiou-Nana MI, et al. Itraconazole for the treatment of pulmonary aspergillosis in heart transplant recipients. Clin Transplant 1998; 12: 30-34.

54. Gaviria JM, van Burik JA, Dale DC, Root RK, Liles WC. Modulation of neutrophil-mediated activity against the pseudohyphal form of Candida albicans by granulocyte colony-stimulating factor (G-CSF) administered in vivo. J Infect Dis 1999; 179: 1301-1304.

55. Paradowski LJ. Saprophytic fungal infections and lung transplantation - revisited. J Heart Lung Transplant 1997; 16: 524-531.

56. Trulock EP. Lung transplantation. Am J Respir Crit Care Med 1997; 155: 789-818.

57. Calvo V, Borro JM, Morales P, et al., and the Valencia 
Lung Transplant Group. Antifungal prophylaxis during early postoperative period of lung transplantation. Chest 1999; 115: 1301-1304.

58. Goodman JL, Winston DJ, Greenfield RA, et al. A controlled trial of fluconazole to prevent fungal infections in patients undergoing bone marrow transplantation. $N$ Engl J Med 1992; 326: 845-851.

59. Slavin MA, Osborne B, Adams R, et al. Efficacy and safety of fluconazole prophylaxis for fungal infections after marrow transplantation. A prospective, randomized, double blind study. J Infect Dis 1995; 171: 1545-1552.

60. Sobh M, El-Agroudy A, Moustafa F, Harras F, ElBedewy M, Ghoneim M. Coadministration of keto- conazole to cyclosporin-treated kidney transplant recipients: a prospective randomized study. Am J Nephrol 1995; 15: 493-499.

61. Warnock DW. Fungal complications of transplantation: diagnosis, treatment and prevention. $J$ Antimicrob Chemother 1995; 36: Suppl. B, 73-90.

62. Denning DW, Venkateswarlu K, Oakley KL, et al. Itraconazole resistance in Aspergillus fumigatus. Antimicrob Agents Chemother 1997; 41: 1364-1368.

63. Working Party of the British Society for Antimicrobial Chemotherapy. Chemoprophylaxis for candidosis and aspergillosis in neutropenia and transplantation: a review and recommendations. J Antimicrob Chemother 1993; 32: 5-21. 